\title{
Is Cloud Computing the Silver Lining for European Schools?
}

\author{
Ingo K. Bosse ${ }^{1}$, Niamh Armstrong ${ }^{2}$, Daniela Schmeinck ${ }^{3}$ \\ ${ }^{1}$ TU Dortmund University, Germany \\ ${ }^{2}$ Mary Immaculate College, Ireland \\ ${ }^{3}$ University of Cologne, Germany
}

\begin{abstract}
Cloud computing can be a key driver for innovation and transformation in learning and teaching. The School on the Cloud network aims to explore new, dynamic ways to educate. The 57 partners involved in the project bring insights from 18 European Countries. They investigate how education should respond to the potential of Cloudbased tools and technologies, the impact they are having on education stakeholders and the longerterm impact they will have on the education sector as a whole. The network has published 59 case studies of good-practices based on their analysis of the perspectives of the role played by both teachers and learners. Firstly, the research explores the impact of the Cloud on the roles of learners and discusses how new technology can be used by teachers as a valueadded component in education. Secondly, the study presents a manual on how to implement Cloudrelated learning and teaching.
\end{abstract}

\section{Introduction}

As technology has become an agent of immense change, it has forced change upon the education system. In the future, Cloud computing is likely to have a significant ripple effect. Changes in Europe, and throughout the world, require students and teachers to adapt to new ways of understanding, new knowledge, attitudes and skills to work and live. Financial and cultural, especially multi-cultural, changes in society touch all levels of education including the diversification of the structure of curricula, the introduction of new subjects, and the adoption of new perspectives. In addition, these changes require the introduction of new teaching tools and approaches, which are adapted to new teaching methods in order to enhance the thinking process.

Children and young people now live and learn in two different worlds: inside and outside school. Bringing together these worlds in a way which focuses on learning will enhance learning in both settings. A considerable degree of learning takes place outside school, including learning about friendships and relationships, learning through games, sports and pastimes, learning by reading books, comics and magazines, as well as watching TV and/or surfing the internet. This kind of out-ofschool learning is usually driven by personal interest or perceived needs, rather than the demands of the school curriculum, and is very important to young people.

There is a need to focus on:

- Investigating didactic processes via ICT;

- Strengthening the goal of each subject into an integrated curriculum;

- Taking into the consideration the target group and their cognitive background.

The European Commission adopted a strategy for "Unleashing the Potential of Cloud Computing in Europe" September 2012. The strategy sets targets to deliver 2.5 million new jobs and boost European Union GDP by $€ 160$ billion (around 1\%) by 2020 . In the European Cloud Partnership (ECP), education perspectives are so far not included in the remit. [1] The European Cloud Initiative includes:

- "actions to provide solutions for Europeanwide certification, including elements of network and information security,

- personal data protection,

- $\quad$ service level agreements,

- interoperability and data portability,

- contractual terms and conditions,

- the prospect of a European cloud services capability,

- and the establishment of a European Research Open Science Cloud" [2]

Innovation in technology in education should be encouraged to reduce the ICT skills gap. A strong digital economy is important to sustain an innovative successful Europe. Cloud computing is an integral part of this innovation and economic development as more ICT skilled professionals are needed to support and develop all sectors of the economy. [1] Learning and teaching has changed to lever the collaborative and 'always on' availability of material to learn and discover. Collaborations and communications over cloud systems are ubiquitous in the digital culture of social spaces and this should be mirrored in the learning spaces. Effective use of the plethora of tools available to complement teaching spaces is paramount. Education needs to move from an 
individualist knowledge acquisition culture towards collaborative knowledge creation culture of learning. [3]

\section{The i-Learner}

In this new educational environment, personalised learning should take a central place. In order for this to happen it is first necessary to analyse what personalised learning exactly is. Although many definitions and interpretations exist, there is general consensus that personalised learning places the learner at the centre, actively designing the learning goals, deciding how to access and acquire information, and owning the learning. To make this possible, the existing virtual learning environment (VLE) must be transformed into real personal learning environments, using an adapted pedagogy that makes i-Learning possible.

Working Group 3 named i-Learner explores the impact of the Cloud on learners, focusing on how new technologies and Cloud applications can enhance personalised and individualised learning. Firstly, the group conducts an analysis of European and international literature on personalised learning related to Cloud-based learning. The state-of-the-art analysis and results of the group discussion is followed by the analysis of 59 case studies compiled by the members of the school on the Cloud network. Its analysis focuses on the key competences and characteristics of the learner of the future.

The first result that emerges from this process is a project-related definition of personalised learning. There are multiple reasons that have caused the personalisation of learning to become icreasingly important. The Organisation for Economic Cooperation and Development (OECD)" cites the following negative aspects, related to today's teaching and learning approach (2006):

- Limitations imposed by physical space

- Teachers responsible for whole groups at any one time;

- Insufficient use of technology;

- Uniform pace of 'traditional' learning;

- Conservative nature of school organisation;

- Step-by-step progression for all children in an equal way;

- Teaching still not an evidence-based profession;

To put it in a nutshell it has been argued that the foundations of personalisation is "the moral purpose (...) of the conscientious teacher to match what is taught, and how it is taught, to the individual learner as a person" [4], an approach for future educational needs that fosters learning capacity among individual learners [4]. Research on the impact of personalised learning over time often include many different terms, causing confusion and conflicting or incomplete interpretations. However, all definitions and research agree on the following principles:

- Personalised learning starts with the learner and the learner is at the centre;

- The learner is active in designing their learning goals and processes;

- The learner decides how to access and acquire information;

- The learner owns and takes responsibility for learning, and is thus more motivated and engaged in the learning process;

- The learner has the capacity to critically monitor their learning outcomes.

Every learner has their own learning method/skills (speed, approach, interest and experiences), so they should have the opportunity to expand their skills and knowledge, exercise and adjust their learning rhythm according to interests in combination with the curriculum. As the protagonist of the learning process is the learner the learning should be adapted to their previous learning experience, and the learning process should be constructed on this basis. While it is useful to suggest creative activities to guide students towards improving their problem-solving skills, the starting point should remain the student previous knowledge.

In addition to being a tailored curriculum that ensures that teaching and assessment methods 'fit' the individual, personalised i-Learning also develops social practices that enable them to reach their full potential.

The basic idea of personalised learning is for learners to exercise ownership, responsibility and control over their experiences, rather than be constrained by centralised, instructor-controlled learning based on the delivery of pre-packaged materials $[5,6]$. Participation is key to understanding personalised learning, as it is a personal process of meaning-making, in which each participant 'constructs' their own version of the process [7]. According to Verpoorten et al. [6], personalised learning relies on three interrelated theories:

- Constructivism: learning as a process in which the learner actively constructs knowledge, and competences by interacting with their environment

- Reflective thinking: instructional practice should aim learning as well at the level understanding and use as a meta-level of learning

- Self-regulated learning: the cognitive and communication processes through which learners control their learning.

It is important to note that in addition to having access to material to read, websites to explore, and assignments and tests to carry out, learners also have tools to monitor these activities. Several dimensions are interconnected in the notion of personalised 
learning experiences, which can be structured into the following core concepts: ownership, participation, diversity, regulation and reflection.

The next task was to define the term 'i-Learner', starting from the discussion about e-learning. Elearning is a set of models, technologies and processes aimed at the acquisition and use of knowledge through the use of information and computer technologies $[8,9]$. The 'e' refers to an electronic component. The European Commission (EC) describes e-learning as "the use of Internet and new multimedia technologies to advance the quality of learning by providing access to resources and services as well as enabling remote exchange and collaboration" [9]. Its main characteristics are:

- The use of standardised and developed computer technology;

- $\quad$ Time and place independence;

- Flexibility in time-management;

- Interactivity and efficience;

- Active participation;

- Different teaching and learning styles possible;

- Enhance collaborative learning through cognitive interaction among learners;

- Organisational support.

For this reason, it is often seen as an effective tool for distance learning. In this regard, i-Learning is an improved version of e-learning, as it uses e-learning tools and combines these with the basic aspects of personalised learning.

To date, research concludes that in order for personalised learning to come to fruition, students need not only to be able to choose and personalise the tools and content that are available, but also to have access to the necessary framework to support their learning [5]. The balance between a student's choice to meet their needs and preferences and an educational framework provided by the teacher to accomplish the educational goals is the optimum approach to teaching and learning.

\section{The i-Teacher}

The OECD's Teaching and Learning International Survey (TALIS) provides insights into teaching and learning. Knowledge-based economies need the "creation of "knowledge-rich", evidence-based education systems, in which school leaders and teachers act as a professional community with the authority to act, the necessary information to do so wisely, and the access to effective support systems to assist them in implementing change." [10] "Teachers' self-efficacy is an important dimension given teachers' impact on students." [10] The provision of mentoring or induction programmes and continued professional development to teachers is vital. Teachers who are more confident in their teaching are better able to adapt to the dynamics in schools. New Media Consortium (NMC) Horizon Report Europe: 2014 School Edition "European schools are facing key challenges linked to the impact and use of new technology. [11] theories of learning place the learner as the central component in the creation of meaning. Learning is an active, constructive process and not a passive reproductive process. Learners need to orchestrate knowledge and pedagogically meaningful use of ICT can create a suitable environment for learning.

Social and emotional learning (SEL) is the process through which children and adults acquire and effectively apply the knowledge, attitudes, and skills necessary to understand and manage emotions, set and achieve positive goals, feel and show empathy for others, establish and maintain positive relationships, and make responsible decisions.[12]These skills are important for learners to regulate oneself and interact with others effectively both in the classroom and online.

Working Group 2 i-Teacher explores the impact of the Cloud on the role of teachers and trainers, and how to use new technologies and cloud applications to enhance the educational ecosystem.

The group discussion focuses on defining what constitutes 'an innovative teacher', and the characteristics such a teacher should have. Results from the discussion include that an i-Teacher should be open-minded, creative, capable of critical thinking and problem-solving. An i-Teacher needs to have an understanding of curricular and cross-curricular issues. Sharing ideas, cooperating with colleagues, and leadership are necessary skills.

Our next task was to define the competences and training needs of teachers at different stages in their teaching career. This discussion focused on the additional competences an innovative teacher should have, with particular regard to newly qualified teachers (NQT), teachers with experience, additional competences an innovative teacher would possess and competences needed for a team teacher. In the case of newly qualified teachers, it is important that they first acquire an understanding of content, develop appropriate assessments and integrate technology and Cloud services into their teaching practice. Practising teachers should have mastered all the NQT competences and developed competences in teaching students to analyse and synthesise, solve problems and apply solutions to real life problems. They also build reflection into their everyday work and formulate a personal development plan. Our research aimed to define the characteristics of an innovative teacher, covering all previous findings, and includes the application of Cloud and new technologies to ensure differentiation and advanced tools to support their pedagogy. They should also be open to sharing with peers and the community. 
Presentations were developed on the impact of Cloud-based teaching on teachers, the use of social media, mobile devices and recommendations. The group is in the process of developing an online catalogue of recommended Cloud-based concepts (platforms, technology, applications and tools) for teachers. All group members have identified and shared concepts, tools and apps. This catalogue is expected to evolve as new products, applications and technologies emerge. Our research made use of a number of Cloud tools in order to get to know their added value, identify their flaws and integrate the Cloud within the workgroup. "Hybrid forms of learning are advisable, where mobile, digital, virtual, social and physical learning spaces merge." [10]

The main conclusion to date is that the i-Teacher is a concept rather than a person. An innovative teacher can only be realised by cooperating with other people. The workgroup i-Teacher focuses on the team and its competences instead of the individual. We also note the importance of Cloud-training sessions to improve the Cloud-competences of teachers, and the necessity of providing accessibility and interconnectivity for each learner. research from the Programme for International Student Assessment (PISA) demonstrates that many of the world's bestperforming education systems are:"

- guided by clear and ambitious standards aligned with high-stakes gateways and instruction systems,

- with a focus on the acquisition of complex,

- $\quad$ higher-order thinking skills;

- additionally, these systems - have moved from bureaucratic command and control' environments towards school systems in which the people at the frontline have much more control of the way resources are used, people are deployed, the work is organised and the way in which work gets done\|" [13]

This research provides valuable insights into the educational systems teachers are working in.

"The NMC Horizon Report series charts the fiveyear horizon for the impact of emerging technologies in school communities across the globe." [11] The report focuses on key trends, challenges and technology developments that are impacting on primary and secondary schools. ICT influences has changed the role of teachers and socio-digital participation can be seen in the classroom. The increased use of Open Educational Resources (OER) in education and the wealth of content available online will stimulate new models of teaching and learning. European Parliament and the Council (2006) identified eight key competences for Lifelong Learning: communication in the mother tongue; communication in foreign languages; mathematical competence and basic competences in science and technology; digital competence; learning to learn; social and civic competences; entrepreneurship; and cultural awareness and expression. The Framework is the results of a wide stakeholder consultations of the competences needed to become competent in a digital society. The Digital Competence Framework will address the challenges of students' low digital competence. The areas of digital competence citizens need to develop:"

- Information: identify, locate, retrieve, store, organise and analyse digital information, judging its relevance and purpose.

- Communication: communicate in digital environments, share resources through online tools, link with others and collaborate through digital tools, interact with and participate in communities and networks, cross-cultural awareness.

- Content-creation: Create and edit new content (from word processing to images and video); integrate and re-elaborate previous knowledge and content; produce creative expressions, media outputs and programming; deal with and apply intellectual property rights and licences.

- Safety: personal protection, data protection, digital identity protection, security measures, safe and sustainable use

- Problem-solving: identify digital needs and resources, make informed decisions on most appropriate digital tools according to the purpose or need, solve conceptual problems through digital means, creatively use technologies, solve technical problems, update own and other's competence" [14]

The Framework provides a detailed self-assessment grid to allow users to grade their proficiency from foundation level, to intermediate level and to advanced, for all five competencies. This adopted framework provides teachers with a road map of competencies they need and competencies their students should acquire.

The Horizon report Europe signalled Cloud Computing and tablet computing will be more prevalent in schools in one year or less. Schools will adopt educational games within two to three years and personalised learning and virtual and remote laboratories will be features in schools within four to five years. [11]

Even though the rapid change and development of technology has already resulted in the introduction of various new technologies into the classroom, many open questions still remain. A very important question is e.g. the question about student and teacher privacy and student and school data. Many of the new products, tools and services that are cloud based are run by third party services. This means that both, the school and student data is handled by a third party.

The fact that in general the services are available 
without monetary payment simplifies the use of the tools directly in the classroom and led to the fact that many new cloud products and services are already being widely adopted by schools. For many of the free services, supplier seeks to make money not from the sale of the service itself, but from mining and/or scanning the data and profile of the users. The collected data is then used to develop purposeful advertising and marketing profiles.

Additionally, the easy access and availability of the services led to the fact that teachers easily apply the services in their classes. Thus there is a lack of formal procurement process in which regulatory compliance and other similar issues are evaluated.

The projects analysis of 59 case studies presented as well as the discussion between the partners during the project meetings showed that privacy aspects and safety issues are dealt very different within the European countries - ranging from complete rejection up to thoughtless use of cloud based services. In some cases even up to ignorance of privacy rights.

As a consequence, educational institutions, teachers, parents as well as the children themselves always need to critically address the question to what extend privacy issues, data ownership and confidentiality and so on are affected by the use of specific services.

The projects analysis of 59 case studies presented the Cloud as a key driver for change and innovation in education, but predominately it appears to be piecemeal rather than coordinated. The 59 examples of Cloud Computing developments highlighted projects tested, piloted, implemented in education around Europe. They provided a varied from national assessments and reviews, to public and private sector developments. The themes of the case studies researched are e-books, e-portfolio, e-content, digital platforms, web-based knowledge sharing, digital repository, use of tablets/BYOD in schools, class management systems, online communities of practice and staff mobility and training. The predominance of e-resources, e-community and device use, indicates the need for an effective ecosystem to support teachers and trainers. Research from PISA, NMC and the Framework for Developing and Understanding Digital Competence in Europe provide valuable research findings into the education and digital landscape teachers are working in. Schools need to be ecosystems to prepare learners for their future. It is also important that students are including in co-constructing the vision of a new learning space.

\section{Conclusion}

Digital-age students want an active learning experience that is social, participatory and supported by rich media. There is also a growing need to support and encourage learner control over the whole/entire learning process [15].

According to McLoughlin \& Lee [5] many social software tools offer the possibility for the learner to organise their own learning experience (through collaborative working, monitoring, questioning and self-evaluation, various representations) and gives the learner a sense of ownership and control over their own learning and career planning.

To make this possible we need to redesign the existing course managements systems (CMSs) and virtual learning environments (VLEs), which do not fully use and integrate the potential of social media in their current form. Although VLEs can be used to provide and track e-learning courses and enhance face-to-face instruction with online components, they are primarily used to automate the administration of learning by facilitating and recording learner activity. In fact, they are mostly a replica of the traditional classroom learning style, which are content-centric. Many instructors just move all their teaching materials to the system where it is presented uniformly to all learners regardless of their background, learning styles and preferences [16].

Therefore, personal learning environments (PLEs) have emerged as a concept associated with the adoption of a raft of Web 2.0 tools, based on their needs and circumstances that serve to integrate essential learning outcomes [5]. In learner-centric methods, learners are expected to actively engage in the learning process to construct their own learning [16]. The role of teachers - who remain responsible for learners' learning - is evolving towards the role of a "tutor" who guides the learning process if needed.

In order for personalised learning to come to fruition, students need not only to be able to choose and personalise the tools and content that are available, but also to have access to the necessary scaffolding to support their learning [5].

More work is required in this field and both a pedagogic change and a greater personalisation of learning are essential for student-centred, selfregulated and independent learning.

According to latest research, $[4,5]$ pedagogy must:

- Ensure that learners are capable of making informed educational decisions;

- See learners as active participants and coproducers of learning resources;

- Diversify and recognise different forms of skills and knowledge;

- Ensure that school and class organisation based around student progress;

- Create diverse learning environments; and

- Include learner-focused forms of feedback and assessment. 
This smart PLE is able to learn the habits of an individual user and remember them so that the user's experience is less repetitive and more closely tailored to their needs.

School on the Cloud network was formed to explore how education should respond and learn from:

- $\quad$ available Cloud technologies

- $\quad$ existing Cloud-based educational initiatives

- network expertise and experiences

- provide guidance and support to stakeholders [17]

Future developments, related to required skills and competences, will change schools over the next 20 years. In the 21st century, a fundamental transformation in education is needed to address the new challenges and competences required.

School on the Cloud Future Perspectives [17] Seeking links with other research initiatives and Stimulation of further projects, such as:

(i)evaluate future education scenarios on the Cloud; (ii)design, application, and evaluation of contextspecific Cloud-based educational solutions that span across all levels of education, and

(iii)develop and test Cloud-based services and tools able to cater for special educational needs [17]

\section{References}

[1] K. Donert, Y. Kotsanis, (eds.), „Education on the Cloud 2015: State of the Art Case Studies." School on the Cloud Network, Working Group 1, Del. 6.4b, 2015, http://schoolonthecloud.eu.

[2] European Commission: European Cloud Initiative", Publications office, European Union, 2015. https://ec.europa.eu/digital-singlemarket/en/european-cloud-computing-strategy

[3] European Parliament's Committee on Culture and Education, Innovative schools: teaching \& learning in the digital era", Publications office, European Union, 2015. http://www.europarl.europa.eu/studies

[4] OECD, "Personalising Education, Schooling for Tomorrow", OECD Publishing, Paris, 2006. DOI: http://dx.doi.org/10.1787/9789264036604-en.

[5] C. McLoughlin, M.J.W. Lee, Personalized and selfregulated learning in the Web 2.0 era: International exemplars of innovative pedagogy using social software. Australien Journal of Educational Technology, Vol 26(1), 2010, pp. 28-43.

[6] D. Verpoorten, C. Glahn, M. Kravcik, S. Ternier, and M. Specht, "Personalisation of Learning in Virtual Learning Environments. Learning in the Synergy of Multiple Disciplines", 4th European Conference on Technology Enhanced Learning, EC-TEL 2009 Nice,
France, September 29-October 2, 2009 Proceedings, 2009, pp. 52-66.

[7] M. Ainscow, "Responding to the challenge of learner diversity: A briefing paper for the Teaching and Learning in 2020 Review". University of Manchester Faculty of Education, 2006

[8] W. Horton, "E-Learning by Design." Pfeiffer \& Company, 2006.

[9] L. Caporarello, G. Sarchioni, "E-learning: therecipe for success." Journal of e-Learning and Knowledge Society, Vol 10, $\mathrm{N}^{\circ} 1,2014$. http://www.je-lks.org/ ojs/index.php/Je-LKS_EN/article/view/885/863.

[10] OECD, "Creating Effective Teaching and Learning Environments", OECD Publishing, Paris, 2009. https://www.oecd.org/edu/school/43023606.pdf.

[11] L. Johnson, S. Adams Becker, V. Estrada, A. Freeman, P. Kampylis, R. Vuorikari, Y, Punie, Horizon Report Europe - 2014 Schools Edition, Publications Office of the European Union \& The New Media Consortium, European Union, 2014.

[12] CASEL. (2016).'SEL Defined' CASEL research; http://www.casel.org/social-and-emotional-learning/ (26 May 2016).

[13] OECD (2011). PISA 2009 Results: Students On Line: Digital Technologies and Performance (Vol. VI). OECD: Paris, France.

[14]Ferrari, A. (2016) 'The Institute for Prospective Technological Studies', Publications office, European Union; http://ipts.jrc.ec.europa.eu/publications/ pub.cfm?id=6359. (28 May 2016).

[15] J. Dron, "Designing the undesignable: Social software and control" Educational Technology \& Society, Vol 10(3), 2007, $\quad$ pp. 60-71, http://www.ifets.info/journals/10_3/5.pdf.

[16]M. Al-Zoube, "E-Learning on the Cloud", International Arab Journal of e-Technology, Vol. 1, No. 2, June 2009, pp. 58-64.

[17] Panousopoulos H, Donert, K., Papoutsis, P, Kotsanis I. (2015). Education on the Cloud: Researching StudentCentred, Cloud-based Learning Prospects in the context of a European Network, Proc. CELDA 2015, http://tinyurl.com/nghy5ay 